\title{
Liver cancer screening in China: practices and its extended questions
}

\author{
Jian-Guo Chen ${ }^{1,2}$, Yong-Hui Zhang ${ }^{1}$, Ling-Ling Lu', Hai-Zhen Chen ${ }^{2}$, Ai-Guo Shen², Yuan-Rong Zhu ${ }^{1}$ \\ 'Department of Epidemiology, Qidong Liver Cancer Institute, Qidong 226200, China. \\ ${ }^{2}$ Department of Epidemiology, Cancer Hospital/Institute, Nantong University, Nantong 226361, China.
}

Correspondence to: Prof. Jian-Guo Chen, Department of Epidemiology, Qidong Liver Cancer Institute, Qidong 226200, China; Cancer Hospital/Institute, Nantong University, Nantong 226361, China. E-mail: chenjg@ntu.edu.cn

How to cite this article: Chen JG, Zhang YH, Lu LL, Chen HZ, Shen AG, Zhu YR. Liver cancer screening in China: practices and its extended questions. Hepatoma Res 2019;5:12. http://dx.doi.org/10.20517/2394-5079.2019.03

Received: 7 Jan 2019 First Decision: 6 Mar 2019 Revised: 3 Apr 2019 Accepted: 3 Apr 2019 Published: 26 Apr 2019

Science Editor: Guang-Wen Cao Copy Editor: Cai-Hong Wang Production Editor: Huan-Liang Wu

\begin{abstract}
Screening for liver cancer (hepatocellular carcinoma) in China started in early 1970s with the application of alphafetoprotein (AFP) in high-incidence regions. It has been extended to nationwide areas, emerging from the concepts of conducting screening in populations at-risk with positive hepatitis B surface antigen to the practice programs in rural and urban areas, and finally to the development of recommendations to guide medical practice for health care providers. The implementation of screening for liver cancer has resulted in earlier detection and hence the early curable treatment for patients who have gained short- or long-term survival, and even reduction in mortality rates, although these outcomes are more anecdotal than rigorously evidence-based. AFP or ultrasound examination has been considered as sensitive and specific methods for early detection but are with limitations. The combined use of these two modalities for screening populations at-risk every six months seems to have been reached consensus. The feasibility of screening for liver cancer is still debated because of differing opinions and even opposition to the choice of targeted sub-populations, the intrinsic necessity, and the contributions of the main risk factors among Western countries and China/Asian areas. Yet, the over 51\% of global burden of liver cancer is in China, the solution to the early detection and treatment of liver cancer should fully consider the actual situation in China. The effectiveness of screening for liver cancer is worthy of anticipation.
\end{abstract}

Keywords: Hepatocellular carcinoma, screening, alpha-fetoprotein, ultrasound, early detection, high risk population

\section{INTRODUCTION}

Liver cancer [hepatocellular carcinoma (HCC)] is currently the second leading cause of cancer deaths worldwide, accounting for about $8.2 \%$ of the global burden of cancer ${ }^{[1]}$. China has the most patients with

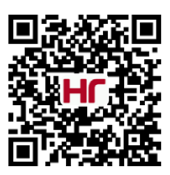


this disease. Based upon the Chinese Cancer Registry Annual Report 2016, the incidence and mortality rates of liver cancer were 28.17 and 24.70 per 100,000, respectively, thereby contributing to total incident cases of 394 thousand, and total death cases of 346 thousand a year in mainland China ${ }^{[2]}$. Liver cancer has long been a public health challenge in China. While improvements in therapies for this cancer have been developed widely, and have achieved some progress in the past decades ${ }^{[3-6]}$, the overall survival from liver cancer remains unsatisfactory ${ }^{[5-7]}$. This outcome is because the choice of treatment is driven by the cancer stage, the resources available, and the level of practitioner expertise ${ }^{[5]}$. Liver cancer often has no obvious clinical symptoms and signs in its early stages, and the tumor lumps grow quietly and rapidly. Most patients have been detected only in an advanced stage, resulting in limited treatment options and a very poor prognosis. A United States population-based study, for instance, reported that, in 2963 HCC patients diagnosed between 1992 and 1999 , only $13 \%$ of the patients received a potentially curative therapy ${ }^{[8]}$.

Recent survival rate data show that the 5-year survival rates of liver cancer from population-based cancer registries in China were around $9.8 \%-12.1 \%{ }^{[9]}$, and that the 5 -year survival rate of liver cancer from a hospital-based cancer registry was $11.69 \%{ }^{[7]}$. Furthermore, the 5 -year survival rate from clinical series of data was $4.8 \%$ in $1958-1970,11.2 \%$ in $1971-1982$, and $45.4 \%$ in $1983-1994$ for patients who received surgical resection ${ }^{[10]}$; and $63.8 \%$ for patients who had resection of small liver cancer ${ }^{[11]}$. The 5 -year relative survival rates for liver cancer during 2002-2012 in Taiwan were 52.0\% for stage I, 2.9\% for stage IV and $28.9 \%$ for all stages ${ }^{[12]}$. A recent Australia report based on cancer registration shows that the 5-year survival was $5 \%$ during the years 1984-1993, and 16\% during 2004-2013 ${ }^{[13]}$. A current multicenter retrospective investigation shows that the overall survival is $19.6 \%$, and is derived from 18,275 liver resection patients with HCC in China ${ }^{[14]}$.

The fact that small or early stage liver cancer had better outcomes for survival has long been recognized ${ }^{[11]}$, and attracted great efforts for the early detection of liver cancer by mass screening in the general population since the 1970s. In the Qidong area, for instance, population-based mass screening programs were first applied to field practice ${ }^{[15,16]}$ when alpha-fetoprotein (AFP) was established to be synthesized in cancer of the liver, and had been proven to be a serological test for this cancer ${ }^{[17,18]}$.

In the past 4 to 5 decades, the application value of AFP and the screening benefit for early detection has demonstrated the mixed results ${ }^{[15-23]}$. So far, there is no internationally recognized program of screening for the cancer of the liver, nor has a scientific consensus been formed in the academic world. Yet, case reports and research reports have provided evidence that screening is an effective way to achieve early detection, early diagnosis and opportunity for early treatment for liver cancer. Screening may have positive and important significance to improving prognosis and reducing mortality, especially in epidemic areas of hepatitis B/liver cancer. Here we describe and review the practice of the screening for liver cancer and discuss the problems arising from this approach.

\section{DISCOVERY OF AFP AND ITS CLINICAL APPLICATION}

After Bergstrandh and Czan discovered alpha-fetoprotein (AFP) in human fetal serum in the 1950s, former Soviet scholar Abelev discovered that AFP was mainly synthesized from placenta and yolk sac, and correspondingly AFP could be detected in both human and mammalian embryo serum ${ }^{[17,18]}$. AFP begins to be synthesized at 6 weeks of gestation and peaks at 12-15 weeks (AFP in fetal plasma can reach $3 \mu \mathrm{g} / \mathrm{L}$ ). After birth, AFP synthesis is inhibited (content reduced to $50 \mu \mathrm{g} / \mathrm{L}$ ); at the end of 12 months, the concentration is close to the adult level. Plasma AFP concentration in healthy adults is lower than $20 \mu \mathrm{g} / \mathrm{L}^{[24]}$. However, AFP would be re-expressed when hepatocytes become cancerous or have severe injury or other forms of diseases ${ }^{[17,25]}$. Human hepatic stem cells (hHpSCs) are currently considered to express $\mathrm{AFP}^{[26]}$.

The probable association of AFP with liver diseases and liver cancer was noted in the 1960s. Tatarinov et al. ${ }^{[27]}$ and O'Conor et al. ${ }^{[28]}$ found that AFP was detected in the serum of patients with liver cancer; and a human 


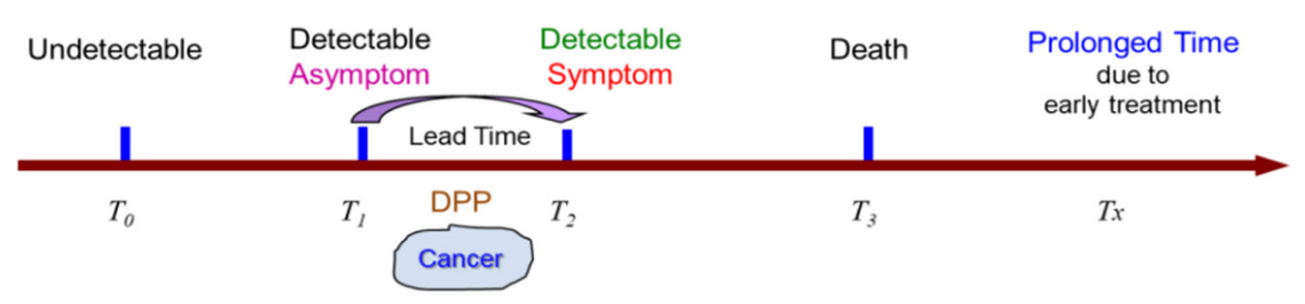

Survival length of patients clinically diagnosed

$$
\left(T_{3}-T_{2}\right)
$$

Survival length in cases screened (with lead time)

$$
\left(T_{2}-T_{1}\right)+\left(T_{3}-T_{2}\right)=T_{3}-T_{1}
$$

Survival length increased time benefit from prompt treatment

$$
\left(T_{2}-T_{1}\right)+\left(T_{3}-T_{2}\right)+T x=T_{3}-T_{1}+T x
$$

Figure 1. Schema for cancer detection and survival time

AFP variant was isolated in $1970^{[29]}$. However, since the relationship between AFP and liver diseases was not very clear, and the incidence of liver cancer in some developed countries was not high, the value of applying measures of AFP in the clinical diagnosis of liver cancer was totally ignored for a long time.

Fortunately, AFP detection technology was quickly introduced to China, and applied in high-risk areas of liver cancer, such as in Jiangsu (Qidong), Guangxi (Fusui), and Shanghai. From 1971-1976, 1,967,511 people were screened for serum AFP in the Shanghai general population: 300 patients with liver cancer were detected, of them, $134(44.7 \%)$ cases were diagnosed as subclinical $\mathrm{HCC}^{[30]}$. During the period of 1974-1980 in Qidong, 1,310,871 people were screened for serum AFP, 499 patients with liver cancer were found, 177 (35.5\%) patients being at early stage ${ }^{[15]}$. These results and subsequent studies have shown that AFP is a useful marker for the early detection of liver cancer ${ }^{[16]}$.

\section{RATIONALE FOR SCREENING}

The overarching principles for screening are prevention and early detection. A detectable early cancer stage must exist for reasonable duration of time to allow the screening test to pick it up ${ }^{[31]}$. Hence screening trials must be based on an understanding of the natural history of the disease. From the view of clinical observation, any disease will have two states: an undetectable disease (normal) state, and a detectable disease state with symptoms or asymptom. Asymptomatically detectable, also known as the "detectable preclinical phase" (DPP $)^{[32]}$, detectable and curable preclinical phase (DCPP $)^{[33]}$, or "pre-clinical detectable phase $(\mathrm{PCDP})^{\mu,[34,35]}$, is the ideal stage for early diagnosis. At this stage, it is possible to detect the disease and even reverse the disease through active and curable treatments. When the cancer was detected in the symptomatic stage, the disease was often developed fully, and showed the medium- or late-stage clinical manifestations. As to screening, a disease that can be detected asymptomatically is a disease suitable for screening. Liver cancer could have abnormal changes of AFP at early phase, vary from several months to several years before the appearance of subjective symptoms, thus providing a possibility for early detection of liver cancer.

In the debate about whether screening can prolong the survival rate of liver cancer, lead time is a key word that cannot be circumvented. Lead time is the time by which diagnosis is anticipated by screening with respect to the symptomatic detection of a disease, or is the time by which the diagnosis has been made in advance by screening ${ }^{[36]}$. Any screening program, including surveillance for liver cancer, is subject to lead time bias ${ }^{[23,31,35,37-40]}$. The relation of the lead time, natural survival length, and the prolonged time due to prompt treatment after screening may be expressed as Figure 1. 
Assuming that any disease or the carcinogenic process started at $T_{o}$, and developed before the time $T_{1}$, this evolution process $\left(T_{1}-T_{0}\right)$ is undetectable. After the point $T_{1}$, the disease (cancer) is asymptomatic but can be detected, until the point $T_{2}$, when symptoms occur. This length of time $\left(T_{2}-T_{1}\right)$ is called lead time, or "detectable preclinical phase" (DPP), and also "sojourn time". In the absence of any screening test, a patient may be diagnosed as an outpatient due to symptoms and/or signs, and then experiences a natural disease course accompanying the process of healing and rehabilitation until the end of life $\left(T_{3}-T_{2}\right)$. Obviously, screening cases will survive with "cancer" for an additional time (lead time: $T_{2}-T_{1}$ ); therefore, their full survival time will be $\left(T_{3}-T_{2}\right)+\left(T_{2}-T_{1}\right)=T_{3}-T_{1}$, which is "longer" than the survival time $\left(T_{2}-T_{1}\right)$ of the outpatient cases. This "increase" in time essentially has no clinical significance for the patient, but it is artificially diagnosed earlier as a cancer. However, the real purpose of screening is to enable timely treatment of cases that are diagnosed early, and hence to prolong the time $\left(T_{3}-T_{2}\right)$ benefit from the prompt treatment, whose increment is assumed to be $T x$. Thus, the survival time of the cases after actual screening is $\left(T_{3}-T_{2}\right)+\left(T_{2}-T_{1}\right)+T x$, or, $T_{3}-T_{1}+T x$, where $T x$ is the patient's real extension of survival length due to early detection and treatment.

\section{MEANS OF SCREENING IMPLEMENTATION}

It is possible to achieve the intended purpose of screening by mastering the principles of screening, identifying the target population for screening, using appropriate tests/examination or diagnostic tools, and relying on reliable and effective treatment. In terms of liver cancer screening, the evidence supporting feasible means of screening in populations at-risk or of specific individuals are summarized as follows.

\section{Major risk factors should be point of focus}

Epidemiological studies have confirmed the main risk factors for liver cancer in China, and high-risk areas as well as high-risk groups (populations) of liver cancer can be defined scientifically ${ }^{[5,16,19,41-44]}$. In accord with recent understanding, the risk factors for primary liver cancer may be categorized into 3 group ${ }^{[41,45]}$ : (1) established factors: chronic HBV infection, chronic HCV infection, alcoholic cirrhosis, dietary aflatoxins, tobacco smoking; (2) likely factors: diabetes mellitus, inherited metabolic disorders- $\alpha-$ antitrypsin deficiency, hemochromatosis, porphyria cutanea tarda, cirrhosis of any etiology, obesity; and (3) possible factors: decreased consumption of vegetables, oral contraceptives, high parity, ionizing radiation, organic trichloroethylene solvent, clonorchis sinensis infection. However, as a population screening strategy, it is impossible to consider all of these etiological factors or risk factors. Moreover, some characteristics of disease or risk factors need to be confirmed in advance by specific test methods; in addition, factors that are considered "established" and "likely" in some areas may only be "possible", or even "not possible" in other regions. For instance, liver fluke infection may be a "very likely" important risk factor for cholangiocarcinoma (CC) in Southeast Asia and Guangdong-Guangxi regions ${ }^{[46,47]}$; Hepatitis C virus (HCV) is considered to be the established factors in many countries ${ }^{[48-50]}$, but these factors seem "impossible" in the etiology of liver cancer in some regions such in Qidong, Jiangsu ${ }^{[41,51]}$. The other example is the nonalcoholic fatty liver disease (NAFLD), which is becoming an increasingly important health issue nowadays in China, with an overall pooled prevalence of $20.09 \%(17.95 \%-22.31 \%)^{[52]}$. It is considered as an alarming important risk factor of HCC development ${ }^{[53]}$. Therefore, population screening in high-incidence areas should be implemented in conjunction with the major local risk factors that can be easily identified within the general population.

\section{AFP could be used as a useful marker}

AFP has been shown to be a sensitive and specific marker for screening ${ }^{[17,18,54-57]}$. In the early stage of liver cancer, abnormal levels (>20 $\mu \mathrm{g} / \mathrm{L}$ ) can be detected in serum, which can ensure that most patients with liver cancer have a long enough DPP characterized with positive AFP even 2 years before the clinical presentation of liver cancer ${ }^{[58]}$. When an AFP cut-off of $20 \mu \mathrm{g} / \mathrm{L}$ is used, the sensitivity and specificity of AFP for HCC were in the range of $41 \%-65 \%$ and $80 \%-95 \%$, respectively ${ }^{[56,59-61]}$; and the sensitivity and specificity of AFP would be changed if the cut-off value is modified $^{[56,62]}$. In Qidong's screening program the sensitivity and 
specificity were $55.3 \%$ and $86.5 \%$, respectively ${ }^{[19]}$. A systematic review evaluating AFP in cirrhotic patients with HCV infection showed sensitivities and specificities of $41 \%-65 \%$ and $80 \%-94 \%$, respectively, for HCC diagnosis ${ }^{[63]}$. In a Taiwan study, screening with AFP was reported to be feasible screening marker of risk identification, and could result in good prognosis in an aged population ${ }^{[64]}$. A recent report in a South East Scotland HCC Surveillance Study (January 2009 and December 2014) ${ }^{[65]}$ showed that AFP as an HCC surveillance tool detects a significant number of treatable HCC in patients with satisfactory outcomes. They also found that the use of serum AFP in HCC surveillance has facilitated the early diagnosis of HCC in a large proportion of the patients undergoing HCC surveillance in whom the HCC was otherwise not detected by ultrasound (US) alone, and that AFP should be included in the liver cancer surveillance ${ }^{[66]}$.

\section{US could be used for early detection}

The application of US and other imaging modalities facilitate localized diagnosis for liver cancer. In the 1980s, US examination began to be used widely in the clinical detection of liver diseases in China. The advantages of US are manyfold. It is non-invasive, produces no radioactive damage, is easy to repeat, has high sensitivity and at a relatively low cost. US is considered as the preferred method for liver cancer localization in screening ${ }^{[6,67,68]}$. US has a sensitivity of $60 \%-80 \%$ and a specificity of over $90 \%$ when it is done expertly ${ }^{[69]}$. An early prospective study reported in the United States in $1985^{[70]}$ showed that in the initial screening for 528 patients, 17 liver cancer patients were found after an average follow-up of 1.4 years. In tumors $<5 \mathrm{~cm}$, AFP levels were normal in $46.2 \%, 20-400 \mu \mathrm{g} / \mathrm{L}$ in another $46.2 \%$, and only $7.6 \%$ were over $400 \mu \mathrm{g} / \mathrm{L}$. Another 7 patients were found by further follow-up to have cancer varying from 1.6 to $4.7 \mathrm{~cm}$, with normal serum AFP levels in 3 cases. Hence the authors concluded that real-time ultrasonography is more sensitive than AFP assay for the early detection of HCC, and that high-risk subjects should receive this procedure at regular intervals. A randomized trial ${ }^{[71]}$ compared two US periodicities: 3 months $v s 6$ months, in a surveillance of HCC in cirrhotic patients. The results showed that 3-month US detection may find more small focal lesions than 6-months US detection, but does not improve detection rate of small HCC, nor improve the 5-year survival. The efficacy of US screening every 6 months for HCC or CC in a selective high risk group in endemic areas of hepatitis B such as in Thailand, Taiwan have been reported ${ }^{[72-74]}$.

\section{The combined application of AFP and US}

AFP or US detection have their limitations. It is a common practice to combine these two methods for HCC surveillance. Many studies using a combined AFP and US surveillance/screening have proven survival benefit to patients by detecting smaller and curable liver cancers ${ }^{[20,55,61,75-78]}$, US combined with AFP for screening for liver cancer is believed to be superior to AFP alone, but periodic US examination would be expensive, while AFP testing is relatively inexpensive ${ }^{[79,80]}$. At present, computed tomography $(\mathrm{CT})$ and dynamic magnetic resonance imaging (MRI) as robust imaging location techniques for the diagnosis of liver cancer are used widely in clinical practice ${ }^{[81,82]}$. A prospective randomized study comparing two different HCC screening procedures (biannual ultrasonography vs. annual triphasic CT) with biannual AFP has suggested that biannual US is comparable to annual CT in detecting early-stage HCC, with lower $\operatorname{costs}^{[83]}$. So there is no evidence to support the use of CT or MRI for routine liver cancer surveillance/screening; while its disadvantages are obvious: significant cost and radiation exposure ${ }^{[81,82,84]}$. Furthermore, findings are frequently discordant even on both $\mathrm{CT}$ and $\mathrm{MRI}^{[85]}$. In an Alaskan Native screening cohort study during 1983-2012, the cost-effectiveness of two HCC screening methods (by US-alone, or screening by AFP initially and switching to US) was evaluated ${ }^{[86]}$. The sensitivity analysis demonstrated that AFP $\rightarrow$ US was more cost-effective than US-alone over a broad range of differences in sensitivity between the two HCC screening methods. It was also pointed out that for many of the patients in rural Alaska, AFP is the only locally available option for HCC screening, and it could potentially identify patients at high risk for HCC who could benefit from referral for a liver US or CT. Thus, public health officials should evaluate the costeffectiveness of $\mathrm{AFP} \rightarrow \mathrm{US}$ to increase access to HCC screening for persons living in remote communities 
without access to US. A balance between the application of AFP test with or without US in screening should be considered. General speaking, the combination of AFP and US can ensure early detection and improve detection rates, thus enabling early diagnosis for liver cancer ${ }^{[20]}$. As such, the combined use of US and AFP is recommended $^{[5]}$.

\section{Early detection could lead to curable treatment}

Early detection of liver cancer has led to effective early treatment, especially by means of surgical resection, and has led to long-term survival for those treatable patients ${ }^{[11,21,30,76,87]}$, although the lead time due to screening may range from 2 to 6 months (70 to 200 days) ${ }^{[23,37,39]}$. Based upon a study of surveillance in cirrhotic patients, semiannual surveillance maintained a survival benefit over symptomatic diagnosis after lead time adjustment, and this benefit became durable in a long-term perspective ${ }^{[39]}$. In a community-based surveillance program ${ }^{[88]}$, significantly improved survival rates were noted in HCC patients detected by surveillance, and in those who received surgical and loco-regional therapies, indicating that HCC patients identified by surveillance were more suitable for surgical and local regional therapies, and would improve survival and should be included as standard of care for patients with hepatitis B. A recent prospective population-based study in Australia ${ }^{[89]}$ showed that increased survival was associated with participation in surveillance programs and curative treatment. The 1-, and 2-year survival rates for surveillance participants were $79 \%$ and $66 \%$, compared with $49 \%$ and $33 \%$, respectively, for non-participants.

\section{HISTORY OF LIVER CANCER SCREENING IN CHINA}

\section{Pioneering start of screening in high-incidence area}

The most representative region for liver cancer screening was in Qidong ${ }^{[16,19,90]}$ : from the early 1970 s to the early 1980s, a sensitive AFP test was used to detect more than 2 million person-times in the general population from Qidong, including about 1.8 million persons who joined the screening program. More than 1000 cases of liver cancer confirmed by screening, of which early (stage I) cases represented $35 \%{ }^{[15]}$. The practice of screening in this period helped to answer a question of primary importance: could liver cancer be detected at in early stage? - it could be. The application of AFP in population-based screening in the field has demonstrated that it is a simple, easy, sensitive and specific way of detection for liver cancer. A large number of patients with liver cancer at early stage in that period has resulted in the improvement of the overall survival rate $e^{[15,16,30]}$.

\section{Formation of concepts of screening for high-risk populations}

The large requirements in human resources and financial resources for the mass screening of liver cancer impeded further implementation of screening. Screening in the general population was halted in the $1980 \mathrm{~s}$ in Qidong and other areas in China. Based on strategic considerations for early detection and early treatment in the high-incidence area, the role of AFP screening were reevaluated, recognizing that the economic benefits of screening through AFP detection are determined by the preferred choice of the target population at high-risk. The specific age (with high incidence rate), gender (males) and risk factors (such as infection with HBV) of liver cancer should be given prioritized consideration for screening ${ }^{[42]}$. Hence, men aged 3059 who were positive for hepatitis B surface antigen ( $\mathrm{HBs} A g$ ) were identified as high-risk population of liver cancer in Qidong ${ }^{[0,91]}$. In the same time, a Shanghai report suggested that screening should be focused on those aged over 35 or 40 with hepatic diseases for more than 5 years and who are positive $\mathrm{HBsAg}^{[92]}$.

\section{Practice of screening in high-risk populations}

From late 1980s to early 1990s, a selected population of 36,381 males at the ages of 30-59 were screened ${ }^{[19,90,93]}$. 5581 HBsAg carriers were identified, enrolled and then randomly assigned to a periodical screening group (once every six months) or a control group to investigate the effectiveness of screening for liver cancer. This research program and practice has helped to confirm and optimize a scheme of screening in populations at high risk that includes such indicators for periodic screening as the subclinical mean sojourn time, sensitivity and predicted values, the lead time (DPP) and the best interval of screening for liver cancer ${ }^{[19,93,94]}$. 
Table 1. Status of national screening for liver cancer in rural areas (2011-2018)

\begin{tabular}{|c|c|c|c|c|c|c|c|}
\hline & $\begin{array}{l}\text { No. of screened } \\
\text { (areas) }\end{array}$ & $\begin{array}{c}\text { No. of cases } \\
\text { detected }\end{array}$ & $\begin{array}{l}\text { Detection } \\
\text { rate }(\%)\end{array}$ & $\begin{array}{c}\text { No. of early } \\
\text { cases }\end{array}$ & $\begin{array}{l}\text { Early detection } \\
\text { rate }(\%)\end{array}$ & $\begin{array}{c}\text { No. of } \\
\text { treated }\end{array}$ & $\begin{array}{c}\text { Treatment } \\
\text { rate }(\%)\end{array}$ \\
\hline $2011.7-2012.6$ & $7,732(6)$ & 65 & 0.84 & 44 & 67.69 & 58 & 89.23 \\
\hline 2012.7-2013.6 & 14,972 (11) & 119 & 0.79 & 64 & 53.78 & 110 & 92.44 \\
\hline 2013.7-2014.6 & $19,441(13)$ & 100 & 0.51 & 59 & 59.00 & 96 & 96.00 \\
\hline 2014.7-2015.6 & 21,603 (13) & 123 & 0.57 & 75 & 60.98 & 115 & 93.50 \\
\hline 2015.7-2016.6 & $22,460(13)$ & 119 & 0.53 & 78 & 65.55 & 108 & 90.76 \\
\hline 2016.7-2017.6 & 21,024 (13) & 115 & 0.55 & 66 & 57.39 & 113 & 98.26 \\
\hline $2017.7-2018.6$ & $20,194(13)$ & 127 & 0.63 & 92 & 72.44 & 122 & 96.06 \\
\hline Total & 127,426 & 768 & 0.60 & 478 & 62.24 & 722 & 94.01 \\
\hline
\end{tabular}

Data from Ref. ${ }^{[98]}$. ${ }^{\star}$ The diameter of the tumor is less than $5 \mathrm{~cm}^{[96]}$

In the Qidong screening program, the lead time for screened patients with liver cancer was estimated to be 12 month ${ }^{[94]}$. In an Italian study, after 10-year follow-up, they found that the median lead-time calculated for all surveilled patients was 6.5 months (7.2 for semiannual and 4.1 for annual surveillance). Lead time bias accounted for most of the surveillance benefit until the third year of follow-up after HCC diagnosis ${ }^{[39]}$.

\section{Implementation of the national project on cancer early diagnosis and treatment}

In 2004, the China Cancer Foundation launched a project for early diagnosis and treatment of cancer, subsidized by central financial transfer payment program $^{[95]}$, and in 2006 , the demonstration project of early detection and early treatment of liver cancer was officially launched in Qidong, Jiangsu Province and in Fusui, Guangxi Zhuang Autonomous Region where screening was carried out in high risk populations, i.e., male residents aged 35-64 and female residents aged 45-64 with positive HBsAg, who should be followed up every 6 months by using repeat monitoring examinations of combined AFP and US. This project has been described in the "Chinese Technical Scheme for Early Diagnosis and Early Treatment of Cancer ${ }^{[06,97]}$.

\section{CURRENT STATUS AND PROGRESS IN CHINA}

\section{Extensions of the screening program}

After 2010, in order to meet the requirements for expanding the scale of liver cancer screening, two areas of Haimen, Jiangsu Province, and Tong'an, Fujian Province were included into the National screening project. Later on, Gong'an, Yidu, Yingshan, Dangyang, Honghu, Huangzhou, Jiayu of Hubei Province, Zherong of Fujian Province, Chongzuo, Guigang, Cenxi, Wuming of Guangxi Zhuang Autonomous Region, Zhongshan of Guangdong Province, and Huanchi, Shangdan of Gansu Province, were included into the program as well. At that time there were 19 areas included in the program, but some of them withdrew after one or more years, with 13 counties (cities) remaining nowadays. From 2007 to 2018, individuals with positive HBsAg have been repeatedly screened 146,637 times; 965 liver cancer patients were found/detected. The annual detection rate was $0.66 \%$, the early detection rate was $62.38 \%$, and the treatment rate was $91.09 \%$. Among them, 127,426 high-risk individual-times were screened during the period of 2011-2018, and 768 liver cancer patients were found/detected. The detection rate was $0.60 \%$, the early detection rate was $62.24 \%$, and the treatment rate was $94.01 \%[\text { Table } 1]^{[98]}$.

\section{Cancer Screening Project in Huaihe River Region}

A cancer screening program (include liver cancer) was issued by the Bureau of Disease Control of the National Health Commission of the PR China in 2008 which has included Sheyang of Jiangsu Province, Fuyang, Suzhou of Anhui Province, Wenshang of Shandong Province, and Xiping, ShenQiu of Henan Province ${ }^{[99]}$. Now this program has been increased to 32 counties (cities) in four Provinces, and has screened more than 53,400 person-times. The results on the screening of liver cancer have not been reported.

\section{Cancer Screening Program in Urban China}

In 2012, the National Cancer Center of China proposed a Cancer Screening Program in Urban China (CanSPUC), which is also a National Major Medical Reform Project that includes screening for cancers of 
the lung, colon-rectum, upper digestive tract (esophagus and stomach), and liver. Residents at ages of 4069 were enrolled into the screening groups. About one to two medium-sized or more cities in each of 14 Provinces/Municipalities across the country joined the project. During the first 5-year round (2012-2016) of screening, it aimed to cover areas of some 3,500,000 of the population, and to screen about 700,000 individuals at high risk ${ }^{[100]}$. So far, 42 cities of 20 provinces were included into CanSPUC. However, there have not been any reports to show the findings of the detection rate or the effectiveness of screening for liver cancer, except on medical expenditures for liver cancer in urban China. The CanSPUC program analyzed the medical expenditure for liver cancer during 2002-2011 in urban areas of China ${ }^{[101]}$ and found that the medical expenditure per case for liver cancer diagnosis and treatment was $¥ 31,020(\$ 4,528)$ from the year 2002 to 2011 and $¥ 35,248 \quad(\$ 5,146)$ from the year 2009 to 2011 , indicating that the economic burden of liver cancer is high in China and the related medical expenditures are increasing.

\section{Recent advances in screening from 2 rural areas}

As one of the bases for demonstration of early detection and early treatment of liver cancer, Qidong launched its Special Fiscal Transfer Payment Project of the Central Government in 2006 ${ }^{[97]}$. The screening scheme followed the recommendations of the Expert Committee of Early Detection and Early Treatment by China Cancer Foundation ${ }^{[96,98]}$. The high risk population screened was defined as those with positive HBsAg at ages of 35-64 for men and of 40-64 for women. Periodically diagnostic screening by using combined methods of AFP and US monitoring were recommended. Since 2007, a target population of 38,016 has been screened in the Qidong area: 3,703 (9.74\%) individuals with positive HBsAg were found. Excluding for 29 patients with liver cancer at the initial screening, 3,674 persons in the cohort were followed up until the 31st of March, 2016. The 268 patients with liver cancer were detected from the 33,199 person-times screened, with an annual detection rate of $1.12 \%$. Of them, 186 patients were found via repeated periodic screening (Group A), in which 149 patients were the early cases, with an early detection rate of $80.11 \%$. Some participants with positive HBsAg were not followed by the suggested periodical screening schedule, but they ( 82 cases) were diagnosed as outpatients within the intervals of screening points (Group B). Calculated by the life-table method, the 1-, 3-, 5-, and 8-year survival of all patients with liver cancer in Group A were 77.16\%, 49.04\%, $38.53 \%$, and $24.25 \%$, and in Group B were $36.25 \%, 21.21 \%, 21.21 \%$, and $0 \%$, respectively, with significant differences between two groups $(P<0.01)$. This finding shows that the screening of individuals at highrisk with semiannual AFP and US detection is effective not only in increasing detection rate of early stage liver cancer but also in improving patients' survival. Ji et al. ${ }^{[102]}$ reported another example from Zhongshan, Guangdong Province that started in 2012. The biannual screening also used serum AFP and US examination for subjects positive for HBsAg. Of the 68,510 eligible residents, 17,966 were screened for HBsAg. Within the first 4 years of follow-up, 57 incident cases of liver cancer (43 from 2,848 HBsAg-positive participants, 14 from 15,118 HBsAg-negative participants) were found. Compared with cases (104) identified from nonparticipants $(50,544)$, the cases detected among screening participants were more likely to be at early stage and had better survival than those among non-participants. The 1-, 3-year overall survival rates for liver cancer cases in the screened group were $48.7 \%$ and $29.1 \%$; and in non-screened group were $36.9 \%$ and $15.5 \%$, respectively, showing better prognosis in screened group ( $\mathrm{HR}=0.64,95 \% \mathrm{CI}: 0.42-0.98$, after adjustment for gender and age). However, this screening study did not show a reduction in liver cancer mortality within the first 4 years of follow-up by comparison of the two groups ( $\mathrm{RR}=1.04,95 \% \mathrm{CI}: 0.68-1.58$ ).

\section{GLOBAL DISPUTES AND CONSENSUS ON LIVER CANCER SCREENING}

\section{Notable randomized trials of screening from China}

Whether liver cancer is suitable for screening, or whether screening has a significant effect, has caused much controversy globally. As one of the methods of cancer control, the values of population screening are often disputed because of differences in understanding of goals, benefits, disadvantage, costs, and potential adverse effects of screening, and of disagreements in assessing the effectiveness of screening ${ }^{[103]}$. Two randomized trials of screening for liver cancer were published in early this century: one from Qidong 
in $2003^{[19]}$, one from Shanghai in $2004^{[20]}$, in which both screened carriers of HBsAg every 6 months. In the Qidong study, the percentage of cases in stage I were significantly higher in the screening group (29.6\%) than in control group (6.0\%), showing short survival benefit from screening, but no difference in 5-year survival between the groups. The mortality rate in the screened group (1,138 per 100,000 person-years) was not significantly different from that in the controls $(1,114$ per 100,000). This trial concluded that screening with AFP resulted in earlier diagnosis of liver cancer, but the gain in lead time did not result in overall reduction in mortality in this reported period. In the Shanghai study, the authors reported that the HCC mortality rate was significantly lower in the screened group (83.2 per 100,000) than in controls (31.5 per 100,000), with a mortality rate ratio of 0.63 (95\%CI: 0.41-0.98). It concluded that the biannual screening with combined AFP and US in individuals aged 35-59 years reduced HCC mortality after 5-year follow-up. These two trials have been noticed and/or cited by over a hundred reports or guidelines, irregardless of whether they were in support or opposition to screening ${ }^{[5,8,21,57,68,103-108]}$.

\section{Screening recommendation in Western countries}

After China's randomized trials were published, the benefit from screening in people at high risk was noted by professional societies, such as AASLD ${ }^{[21,105,108]}$, simply because of the surveillance/screening for liver cancer had become widely applied, but, there was no evidence of benefit from it worldwide. In these guidelines on management of HCC, the two randomized trials performed in China mentioned above were evaluated. The guideline authors were interesting in the result of HCC related mortality that was reduced by $37 \%$ throughout the screening for 18,816 individuals with HBV infection in Shanghai, and added positive comments that these results probably represent the minimum benefit that can be expected from surveillance, because of poor compliance of less than $60 \%{ }^{[20]}$. They also cited the earlier study conducted in Qidong ${ }^{[19]}$ that failed to show long term survival/mortality-reduction benefit due to patients who were diagnosed with liver cancer did not undergo appropriate treatment, and suggested that these results should be validated in other geographical areas, and that assessing the benefits of surveillance by RCT are still considered necessary ${ }^{[21]}$. Since the recommendation was issued, other guidelines or suggestions have been published ${ }^{[106-110]}$, and various studies have examined physicians' knowledge of or adherence to the guidelines and reported deficiencies and need for improvement ${ }^{[81]}$. Most gastroenterologists correctly identified the common highrisk scenarios, methods, and interval of HCC screening as recommended by AASLD ${ }^{[111]}$. A recent systematic review on surveillance detection demonstrated improved survival and increased detection rate of early stage HCC $^{[68]}$. Forty-seven studies from January 1990 through January 2014 with 15,158 patients were identified, of whom 6,284 (41.4\%) had HCC detected by surveillance, being associated with improved early stage detection (OR: 2.08, 95\%CI: 1.80-2.37) and curative treatment rates (OR:2.24, 95\%CI:1.99-2.52). HCC surveillance was associated with significantly prolonged survival (OR: 1.90, 95\%CI: 1.67-2.17), even after adjusting for leadtime bias. It is believed that HCC surveillance is associated with significant improvements in early tumor detection, receipt of curative therapy, and overall survival in patients with cirrhosis ${ }^{[75]}$, and may also reduce the mortality of $\mathrm{HCC}^{[20,74]}$.

\section{Debates on screening effectiveness}

Although the effectiveness of liver cancer screening has been recognized in the literature and is also included in the AASLD surveillance guidelines for liver cancer ${ }^{[55,21]}$, there have been different opinions and even opposition to the choice of at-risk populations, the necessity, and the effectiveness of screening. Lederle and Pocha ${ }^{[112]}$ were opposed to the existing screening programs by criticizing the 2005 AASLD recommendations for HCC screening ${ }^{[21]}$, arguing that the recommendations were based upon trials from China ${ }^{[19,20]}$, which failed to account for clustering in the analysis (a cluster randomized trial cannot be analyzed at the patient level), hence they state "Ignoring the clustering results in confidence intervals which are too narrow and $P$ values which are too small; hence it is likely to produce spuriously significant differences ${ }^{\$[57,113]}$. Furthermore, they questioned the evidence obtained from the study that is not a level I evidence to support the liver cancer screening, and is not necessarily applicable to Western populations because it was conducted in a hepatitis B population in China, and most HCC in West countries and North America is caused by hepatitis 
$\mathrm{C}^{[21,114]}$. In an editorial comment in the BMJ ${ }^{[115]}$, Law points out that screening of unproved value should not be advocated, and that before any screening for cancer is introduced, large randomized trials with mortality end points should be conducted to establish and quantify any benefit. Evaluation of mortality of liver cancer in a screening population is a point of concern. A recent matched case-control study within the American Veterans Affairs (VA) health care system found that screening patients with cirrhosis for HCC by US or AFP alone, or both tests was not associated with decreased HCC-related mortality ${ }^{[116]}$. Some authors thought that randomized screening trials are bothersome, but there is no second-best option ${ }^{[103,112]}$; others illustrated that RCTs of screening for HCC is difficult and ethically questionable ${ }^{[40]}$, is now not ethically feasible in clinical practice because screening for liver cancer in cirrhotic patients is routine practice for the majority of clinicians ${ }^{[117]}$, even if patients show no interest in such a program ${ }^{[118]}$. In addition, the AFP use in screening has long been criticized because of its lower sensitivity and specificity than imaging modalities ${ }^{[60,119]}$. In the European clinical practice guidelines for HCC, US was seen as the most appropriate test to perform surveillance, but the combination with AFP is not recommended ${ }^{[108]}$. A meta analyses showed that AFP provided no additional benefit to US ${ }^{[69]}$, while others concluded that there is not enough evidence to support or refute the value of AFP or US screening, or both, of HBsAg positive patients for HCC ${ }^{[120]}$. More emphatically, early in this century, it has been stated that "the time has come to bid a fond adieu to $\mathrm{AFP}^{\text {,[121,122] }}$, or it is "the demise of a brilliant $\operatorname{star}^{\text {"? }}$ "123] , as a test for HCC diagnosis and particularly for HCC surveillance.

\section{Consensus on liver cancer screening}

Despite the large debate over liver cancer screening, there is still much consensus on many of the relevant aspects of screening. For example, it is emphasized that the cancer screened must have DPP, or the cancer should be detected early by better sensitive and specific methods; moreover, the appropriate effects of the screening results can be evaluated, and could prolong the survival and may reduce mortality ${ }^{[20,124,125]}$. Many guidelines for the management and monitoring of liver cancer have been issued around the world; for example, they are available in the United States, Europe, and Asia ${ }^{[105-110]}$. However, evaluation of current liver cancer screening has not been carried out in a large scale because there is no consensus on the best strategy for liver cancer screening. On the other hand, it also believed that there is an urgent need to improve the strategies of screening and monitoring for liver cancer, in order to detect early stage liver cancer and improve the survival rate of patients ${ }^{[37,57]}$. The current problem is that, compared to other cancers, the development of globally accepted guidelines seems to be less relevant due to the existence of regional differences in etiologies underlyhing the resultant tumor biology as well as the resources available for management of liver cancer ${ }^{[126]}$. However, in recent years, research and practice of targeted liver cancer screening, screening methods and time intervals have become consistent and reached a point of consensus. For example, screening should be performed in high-risk populations ${ }^{[1,20,22,43,44,72,87,93,108,127]}$; chronic hepatitis B is a high-risk population of liver cancer $^{[128]}$. The cost effectiveness of screening will be principally related to the sensitivity and specificity of the surveillance tools, as well as the efficacy of treatment ${ }^{[123]}$, and surveillance is deemed cost-effective if the expected HCC risk exceeds $1.5 \%$ per year in patients with hepatitis $\mathrm{C}$ and $0.2 \%$ per year in patients with hepatitis $\mathrm{B}^{[105]}$; The screening methods used included AFP and US, with a recommended interval of 6 months ${ }^{[5,19,20,54,55,59,66,75,76,86,108,129-131]}$. In a two-stage screening intervention in Taiwan, potential costeffectiveness compared with opportunistic screening in the target population of an HCC endemic area is reported $^{[132]}$.

\section{PROSPECTS FOR LIVER CANCER SCREENING}

Although there is currently no internationally recognized program for the screening for liver cancer, except for some aspects of the consensus, in the past decades China has experienced many screening trials ${ }^{[15,19,20,90,93,97,100,102]}$, which have fully demonstrated the Chinese characteristics (most patients are HBV-related liver cancer) and the need for the management and control for the one of its most common malignancies. Professional societies in Western countries had proposed recommendations and guidelines 
on this special issue ${ }^{[108]}$, although in the recent American Cancer Society Guidelines, the screening for liver cancer is not mentioned ${ }^{[133]}$. Even in China, there are several clinical practice guidelines for liver cancer $^{[134]}$. Therefore, any users of these guidelines should be aware that the recommendations are intended to guide clinical practice in circumstances where all possible resources and therapies are available; hence, they should adopt the recommendations in the context of their local regulations and/or team capacities, infrastructure and cost-benefit strategies ${ }^{[108,129]}$. Liver cancer nowadays is the second leading cause of cancer deaths worldwide, accounting for about $8.1 \%$ of the global burden of cancer, in which China represents its $51 \%$ of this burden ${ }^{[1]}$. The global solution to the early diagnosis and treatment of liver cancer should fully consider the actual situation in China. We present some suggestions in summary for liver cancer screening/ surveillance.

\section{Combined use of US and AFP are recommended}

So far, AFP remains an effictive screening tool or marker for liver cancer detection, especially in undeveloped countries/areas, on Asia, and even in some areas in developed countries ${ }^{[55-57,65,80,86]}$, because there is no a single "all-in-one" biomarker that fits all-surveillance, diagnosis, or prediction of prognosis ${ }^{[62]}$. In order to improve the sensitivity and specificity of screening and prevent missed diagnosis, the combination use of US and AFP test are strongly recommended. Since about 30\% of liver cancers are negative for serum AFP, novel diagnostic markers need to be established ${ }^{[56]}$. There are no data to support the use of multidetector CT or dynamic MRI for surveillance ${ }^{[108]}$, but one report ${ }^{[133]}$ showed that the sensitivity estimates of CT and MRI for liver cancer detection were 0.70 and 0.86 , respectively, and the combined use was 0.94. CT or MRI could be used for patients with cirrhosis and those suspected cases (such as with AFP positivity) requiring further clinical ascertainment ${ }^{[57,130,135]}$.

\section{Novel diagnostic markers are urgently needed}

In addition to AFP (AFP-L3), DCP, GPC3, GP73, AFU, GGT and others are still recommended as markers for monitoring and diagnosis of liver cancer; DKK1, MDK, and microRNA are also being used as new markers ${ }^{[55,56,62,61,136-141]}$. For instance, a European study found that osteopontin (OPN) is a promising marker for early detection of $\mathrm{HCC}^{[142]}$. In this study, each of $100 \mathrm{HCC}$ cases was matched with 2 controls. Conditional logistic regression model was used to calculate the multivariate OR and $95 \% \mathrm{CI}$ for OPN levels in relation to HCC. The results showed that OPN levels were positively correlated with HCC risk: the multivariate OR was 1.30 (1.14-1.48) for every $10 \%$ increase. For cases diagnosed within 2 years, the combination of OPN and AFP was best able to predict the risk of HCC, indicating that the measurement of OPN and AFP could independently identify high-risk groups in liver diseases. In order to make up for the deficiency of sensitivity and specificity of diagnostic markers such as AFP, novel early diagnosis and early precursory (predictive) markers are urgently needed for research-development and verification.

\section{Translating early detection to effective curable treatment}

According to the current economic conditions and medical conditions (especially in undeveloped countries/areas), screening in high-risk groups of liver cancer every 6 months is particularly appropriate and acceptable. The key for a successful screening program should be a focus on individuals at high risk, conducting repeated or periodical screening and follow-up. Some authors may suggest patients with HCV, NAFLD or with cirrhosis should be screened, but so far there are no data from randomized trials of surveillance to evaluate effectiveness ${ }^{[5]}$. Liver cancer patients found in screening who fail to receive timely treatment will not improve survival and mortality. Any guidelines for screening on liver cancer should emphasize not only the early detection of liver cancer but also access and uptake of early curable or lifeextending treatment.

\section{Effectiveness of screening is in anticipation}

For evaluating the efficacy of population-based cancer screening modalities, the reduction of mortality rate within the screened population is the gold-standard indicator ${ }^{[20,72]}$, but it should not be a mandatory 
requirement, since these outcomes will not be observable for many years ${ }^{[143]}$; survival rate change is indeed a necessary indicator. Any benefits and risks should be compared and reviewed before adopting a certain method of screening ${ }^{[57,117,144]}$. If the risks outweigh the benefits, it cannot be regarded as effective and is therefore not recommended. The surveillance adherence rates should be increased and improved ${ }^{[40,145]}$, and should be supported by patients, providers, and health care systems/governments ${ }^{[37]}$. From the perspective of public health, cost-effective evaluation should be considered, and the benefits and risks of screening should be compared, as well ${ }^{[31,86,144,146]}$. Obviously, benefits of liver cancer screening, at least in terms of greater benefits than harms from the surveillance, have been evident so far.

\section{CONCLUSION}

The success of screening depends on having sufficient numbers of personnel to perform the screening tests by using the technology appropriately or to achieve adequate coverage of the population, and on the availability of facilities that can undertake subsequent diagnosis, treatment, and follow-up, as has been addressed by the $\mathrm{WHO}^{[147]}$. The bulk of available evidence suggests that screening for liver cancer is beneficial, certainly benefits outweigh harms. Inasmuch as symptomatic presentation of liver cancer has an almost universally fatal outcome, screening for liver cancer is an appropriate method that could be used to detect early stage liver cancer in China and other endemic countries/areas where liver cancer burden is substantial. The combined use of AFP and US for liver cancer screening, in the view of its relative cost-effective or applicability in community/population-based screening, are recommended while other novel markers or techniques remain to be developed. High risk individuals with established risk factors (etiological) and or characteristics (clinically identified) are the target populations; and opportunities for screening at-risk persons is to be encouraged even in regions with financial and medical limitations. Only in this way will it be possible to find more early and curable liver cancers.

\section{DECLARATIONS}

\section{Acknowledgments}

The authors would like to thank Prof. Thomas W. Kensler at Public Health Sciences Division, Fred Hutchinson Cancer Research Center, Seattle, Washington for his useful comments and language editing.

\section{Authors' contributions}

Design of the work, data analysis and interpretation: Chen JG

Data acquisition, material support: Chen JG, Zhang YH, Lu LL, Chen HZ

Provided administrative, technical support: Shen AG, Zhu YR

Wrote the manuscript: Chen JG, Shen AG

\section{Availability of data and materials}

Not applicable.

\section{Financial support and sponsorship}

This work was supported partially by the China Cancer Foundation Program, and by Chinese National Key Projects (2012ZX10002009, 2018ZX10732202-001).

\section{Conflicts of interest}

All authors declared that there are no conflicts of interest.

\section{Ethical approval and consent to participate}

Not applicable.

\section{Consent for publication}

Not applicable. 


\section{Copyright}

(C) The Author(s) 2019.

\section{REFERENCES}

1. Bray F, Ferlay J, Soerjomataram I, Siegel RL, Torre LA, et al. Global cancer statistics 2018: GLOBOCAN estimates of incidence and mortality worldwide for 36 cancers in 185 countries. CA Cancer J Clin 2018;68:394-424.

2. He J, Chen WQ. 2016 Chines Cancer Registry Annual Report. Beijing: Tsinghua Press; 2017. pp. 122-5. (in Chinese)

3. Dong W, Zhang T, Wang ZG, Liu H. Clinical outcome of small hepatocellular carcinoma after different treatments: a meta-analysis. World J Gastroenterol 2014;20:10174-82.

4. Xu Q, Kobayashi S, Ye X, Meng X. Comparison of hepatic resection and radiofrequency ablation for small hepatocellular carcinoma: a meta-analysis of 16,103 patients. Sci Rep 2014;4:7252.

5. El-Serag HB. Hepatocellular carcinoma. N Engl J Med 2011;365:1118-27.

6. Forner A, Reig M, Bruix J. Hepatocellular carcinoma. Lancet 2018;391:1301-14.

7. Chen JG, Chen HZ, Zhu J, Yang YL, Zhang YH. Cancer survival in patients from a hospital-based cancer registry, China. J Cancer 2018;9:851-60.

8. El-Serag HB, Marrero JA, Rudolph L, Reddy KR. Diagnosis and treatment of hepatocellular carcinoma. Gastroenterology 2008;134:1752-63.

9. Zeng HM, Chen WQ, Zheng RS, Zhang SW, Ji JS, et al. Changing cancer survival in China during 2003-15: a pooled analysis of 17 population-based cancer registries. Lancet Glob Health 2018;6:e555-67.

10. Zhou XD, Tang ZY. Management of hepatocellular carcinoma: long-term outcome in 2639 cases. Gan To Kagaku Ryoho 1997;24 Suppl 1:9-16.

11. Zhou XD, Tang ZY, Yu YQ, Yang BH, Lin ZY, et al. Long-term results of surgery for small primary liver cancer in 514 adults. J Cancer Res Clin Oncol 1996;122:59-62.

12. Chiang CJ, Lo WC, Yang YW, You SL, Chen CJ, et al. Incidence and survival of adult cancer patients in Taiwan, 2002-2012. J Formos Med Assoc 2016;115:1076-88.

13. Carville KS, MacLachlan JH, Thursfield V, Cowie BC. Hepatocellular carcinoma over three decades in Victoria, Australia: epidemiology, diagnosis and trends, 1984-2013. Intern Med J 2018;48:835-44.

14. Zhang B, Zhang B, Zhang Z, Huang Z, Chen Y, et al. 42,573 cases of hepatectomy in China: a multicenter retrospective investigation. Sci China Life Sci 2018;61:660-70.

15. Zhu YR. Clinical implication of AFP serosurvey. Zhonghua Zhong Liu Za Zhi 1983;5:38-40. (in Chinese)

16. Zhu YR, Chen JG, Huang XY. Hepatocellular carcinoma in Qidong County. In: Tang ZY, Wu MC, Xia RS, editors. Primary liver cancer. China Academic Publisher. Beijing: Springer-Verlag; 1989. pp. 204-22.

17. Abelev GI. Alpha-fetoprotein in ontogenesis and its association with malignant tumors. Adv Cancer Res 1971;14:295-358.

18. Alpert E, Drysdale JW, Isselbacher KJ, Schur PH. Human $\alpha$-fetoprotein. Isolation, characterization, and demonstration of microheterogeneity. J Biol Chem 1972;247:3792-8.

19. Chen JG, Parkin DM, Chen QG, Lu JH, Shen QJ, et al. Screening for liver cancer: results of a randomised controlled trial in Qidong, China. J Med Screen 2003;10:204-9.

20. Zhang BH, Yang BH, Tang ZY. Randomized controlled trial of screening for hepatocellular carcinoma. J Cancer Res Clin Oncol $2004 ; 130: 417-22$.

21. Bruix J, Sherman M, Practice Guidelines Committee, American Association for the Study of Liver Diseases. Management of hepatocellular carcinoma. Hepatology 2005;42:1208-36.

22. Amarapurkar D, Han KH, Chan HL, Ueno Y, Asia-Pacific Working Party on Prevention of Hepatocellular Carcinoma. Application of surveillance programs for hepatocellular carcinoma in the Asia-Pacific region. J Gastroenterol Hepatol 2009;24:955-61.

23. Santi V, Trevisani F, Gramenzi A, Grignaschi A, Mirici-Cappa F, et al. Semiannual surveillance is superior to annual surveillance for the detection of early hepatocellular carcinoma and patient survival. J Hepatol 2010;53:291-7.

24. Tumor Group, Shanghai Institute of Biochemistry, Chinese Academy of Sciences. Progress in A Kind of Fetal Protein. J Biochem Biophys 1977;9:321-37.

25. Kubota H, Storms RW, Reid LM. Variant forms of alpha-fetoprotein transcripts expressed in human hematopoietic progenitors. Implications for their developmental potential towards endoderm. J Biol Chem 2002;277:27629-35.

26. Schmelzer E, Zhang L, Bruce A, Wauthier E, Ludlow J, et al. Human hepatic stem cells from fetal and postnatal donors. J Exp Med 2007;204:1973-87.

27. Tatarinov IuS. Some clinical aspects of the study of embryo specific proteins in hepatitis, cirrhosis and primary cancer of the liver. Vestn Akad Med Nauk SSSR 1970;25:68-73.

28. O'Conor GT, Tatarinov YS, Abelev GI, Uriel J. A collaborative study for the evaluation of a serologic test for primary liver cancer. Cancer 1970;25:1091-8.

29. Purves LR, van der Merwe E, Bersohn I. Variants of alpha-fetoprotein. Lancet 1970;2:464-5.

30. Tang ZY, Yang BH. Secondary prevention of hepatocellular carcinoma. J Gastroenterol Hepatol 1995;10:683-90.

31. Bretthauer M, Kalager M. Principles, effectiveness and caveats in screening for cancer. Br J Surg 2013;100:55-65.

32. Screening for squamous cervical cancer: duration of low risk after negative results of cervical cytology and its implication for screening policies. IARC working group on evaluation of cervical cancer screening programmes. Br Med J (Clin Res Ed) 1986;293:659-64. 
33. Friedman GD, Hiatt RA, Quesenberry CP Jr, Selby JV, Weiss NS. Problems in assessing screening experience in observational studies of screening efficacy: example of urinalysis screening for bladder cancer. J Med Screen 1995;2:219-23.

34. Lai MS, Yen MF, Kuo HS, Koong SL, Chen TH, et al. Efficacy of breast-cancer screening for female relatives of breast-cancer-index cases: Taiwan multicentre cancer screening (TAMCAS). Int J Cancer 1998;78:21-6.

35. Hsu CY, Yen MF, Auvinen A, Chiu YH, Chen HH. Bayesian negative-binomial-family-based multistate Markov model for the evaluation of periodic population-based cancer screening considering incomplete information and measurement errors. Stat Methods Med Res 2018;27:2519-39.

36. Duffy SW, Nagtegaal ID, Wallis M, Cafferty FH, Houssami N, et al. Correcting for lead time and length bias in estimating the effect of screen detection on cancer survival. Am J Epidemiol 2008;168:98-104.

37. Zhao C, Nguyen MH. Hepatocellular carcinoma screening and surveillance: practice guidelines and real-life practice. J Clin Gastroenterol 2016;50:120-33.

38. Day NE, Walter SD. Simplified models of screening for chronic disease: estimation procedures from mass screening programmes. Biometrics 1984;40:1-14.

39. Cucchetti A, Trevisani F, Pecorelli A, Erroi V, Farinati F, et al. Estimation of lead-time bias and its impact on the outcome of surveillance for the early diagnosis of hepatocellular carcinoma. J Hepatol 2014;61:333-41.

40. Costentin CE, Layese R, Bourcier V, Cagnot C, Marcellin P, et al. Compliance with hepatocellular carcinoma surveillance guidelines associated with increased lead-time adjusted survival of patients with compensated viral cirrhosis: a multi-center cohort study. Gastroenterology 2018;155:431-42.e10.

41. Chen JG, Zhang SW. Liver cancer epidemic in China: past, present and future. Semin Cancer Biol 2011;21:59-69.

42. Chen JG. The selection of high risk population for liver cancer: feasibility of mass screening using alpha-fetoprotein. Chin J Prev Med 1990;24:56-7. (in Chinese)

43. Ronot M, Pommier R, Dioguardi Burgio M, Purcell Y, Nahon P, et al. Hepatocellular carcinoma surveillance with ultrasound: costeffectiveness, high-risk populations, uptake. Br J Radiol 2018;91:20170436.

44. Tang A, Hallouch O, Chernyak V, Kamaya A, Sirlin CB. Epidemiology of hepatocellular carcinoma: target population for surveillance and diagnosis. Abdom Radiol (NY) 2018;43:13-25.

45. Stuver S, Trichopoulos D. In: Adami HO, Hunter D, Trichopoulos D, editors. Textbook of cancer epidemiology. New York: Oxford University Press; 2008. pp. 308-32.

46. Parkin DM, Srivatanakul P, Khlat M, Chenvidhya D, Chotiwan P, et al. Liver cancer in Thailand. I. A case-control study of cholangiocarcinoma. Int J Cancer 1991;48:323-8

47. Vatanasapt V, Martin N, Sriplung H, Chindavijak K, Sontipong S, et al. Cancer in Thailand 1988-1991. IARC Tech Rep No. 16, Lyon: IARC; 1993. pp. 64-5.

48. Dondog B, Lise M, Dondov O, Baldandorj B, Franceschi S. Hepatitis B and C virus infections in hepatocellular carcinoma and cirrhosis in Mongolia. Eur J Cancer Prev 2011;20:33-9.

49. Chuang SC, Lee YC, Hashibe M, Dai M, Zheng T, et al. Interaction between cigarette smoking and hepatitis B and C virus infection on the risk of liver cancer: a meta-analysis. Cancer Epidemiol Biomarkers Prev 2010;19:1261-8

50. Mak LY, Cruz-Ramón V, Chinchilla-López P, Torres HA, LoConte NK, et al. Global epidemiology, prevention, and management of hepatocellular carcinoma. Am Soc Clin Oncol Educ Book 2018;38:262-79.

51. Szymañska K, Chen JG, Cui Y, Gong YY, Turner PC, et al. TP53 R249S mutations, exposure to aflatoxin, and occurrence of hepatocellular carcinoma in a cohort of chronic hepatitis B virus carriers from Qidong, China. Cancer Epidemiol Biomarkers Prev 2009; 18:1638-43.

52. Li Z, Xue J, Chen P, Chen L, Yan S, et al. Prevalence of nonalcoholic fatty liver disease in mainland of China: a meta-analysis of published studies. J Gastroenterol Hepatol 2014;29:42-51.

53. Younes R, Bugianesi E. Should we undertake surveillance for HCC in patients with NAFLD? J Hepatol 2018;68:326-34.

54. Bird TG, Dimitropoulou P, Turner RM, Jenks SJ, Cusack P, et al. Alpha-fetoprotein detection of hepatocellular carcinoma leads to a standardized analysis of dynamic AFP to improve screening based detection. PLoS One 2016;11:e0156801.

55. Song P, Tang Q, Feng X, Tang W. Biomarkers: evaluation of clinical utility in surveillance and early diagnosis for hepatocellular carcinoma. Scand J Clin Lab Invest Suppl 2016;245:S70-6.

56. Zacharakis G, Aleid A, Aldossari KK. New and old biomarkers of hepatocellular carcinoma. Hepatoma Res 2018;4:65.

57. $\mathrm{PDQ}{ }^{\circledR}$ Screening and Prevention Editorial Board. PDQ Liver (Hepatocellular) Cancer Screening (PDQ $\left.{ }^{\circledR}\right)$. Bethesda, MD: National Cancer Institute; 2018. Available from: https://www.cancer.gov/types/liver/hp/liver-screening-pdq. [Last accessed on 6 Jan 2019]

58. Heyward WL, Lanier AP, Bender TR, McMahon BJ, Kilkenny S, et al. Early detection of primary hepatocellular carcinoma by screening for alpha-fetoprotein in high-risk families. A case-report. Lancet 1983;2:1161-2.

59. Daniele B, Bencivenga A, Magna AS, Tinessa V. Alpha-fetoprotein and ultrasonography screening for hepatocellular carcinoma. Gastroenterology 2004; 127:S108-12.

60. Kondo Y, Kimura O, Shimosegawa T. Significant biomarkers for the management of hepatocellular carcinoma. Clin J Gastroenterol 2015;8:109-15.

61. Fu J, Wang H. Precision diagnosis and treatment of liver cancer in China. Cancer Lett 2018;412:283-8.

62. Schütte K, Schulz C, Link A, Malfertheiner P. Current biomarkers for hepatocellular carcinoma: surveillance, diagnosis and prediction of prognosis. World J Hepatol 2015;7:139-49.

63. Gupta S, Bent S, Kohlwes J. Test characteristics of alpha-fetoprotein for detecting hepatocellular carcinoma in patients with hepatitis C. A systematic review and critical analysis. Ann Intern Med 2003;139:46-50.

64. Huang YC, Huang CF, Chang KC, Hung SF, Wang JH, et al. Community-based screening for hepatocellular carcinoma in elderly residents in a hepatitis B-and C-endemic area. J Gastroenterol Hepatol 2011;26:129-34. 
65. Bird TG, Dimitropoulou P, Turner RM, Jenks SJ, Cusack P, et al. Alpha-fetoprotein detection of hepatocellular carcinoma leads to a standardized analysis of dynamic AFP to improve screening based detection. PLoS One 2016;11:e0156801.

66. Marrero JA, El-Serag HB. Alpha-fetoprotein should be included in the hepatocellular carcinoma surveillance guidelines of the American Association for the Study of Liver Diseases. Hepatology 2011;53:1060-1; author reply 1061-2.

67. Chiang JK, Chih-Wen L, Kao YH. Effect of ultrasonography surveillance in patients with liver cancer: a population-based longitudinal study. BMJ Open 2017;7:e015936.

68. Singal AG, Pillai A, Tiro J. Early detection, curative treatment, and survival rates for hepatocellular carcinoma surveillance in patients with cirrhosis: a meta-analysis. PLoS Med 2014;11:e1001624.

69. Singal A, Volk ML, Waljee A, Salgia R, Higgins P, et al. Meta-analysis: surveillance with ultrasound for early-stage hepatocellular carcinoma in patients with cirrhosis. Aliment Pharmacol Ther 2009;30:37-47.

70. Sheu JC, Sung JL, Chen DS, Lai MY, Wang TH, et al. Early detection of hepatocellular carcinoma by real-time ultrasonography. A prospective study. Cancer 1985;56:660-6.

71. Trinchet JC, Chaffaut C, Bourcier V, Degos F, Henrion J, et al. Ultrasonographic surveillance of hepatocellular carcinoma in cirrhosis: a randomized trial comparing 3- and 6-month periodicities. Hepatology 2011;54:1987-97.

72. Chen TH, Chen CJ, Yen MF, Lu SN, Sun CA, et al. Ultrasound screening and risk factors for death from hepatocellular carcinoma in a high risk group in Taiwan. Int J Cancer 2002;98:257-61.

73. Siripongsakun S, Vidhyarkorn S, Charuswattanakul S, Mekraksakit P, Sungkasubun P, et al. Ultrasound surveillance for cholangiocarcinoma in an endemic area: A prove of survival benefits. J Gastroenterol Hepatol 2018;33:1383-8.

74. Chaiteerakij R, Chattieng P, Choi J, Pinchareon N, Thanapirom K, et al. Surveillance for hepatocellular carcinoma reduces mortality: an inverse probability of treatment weighted analysis. Ann Hepatol 2017;16:421-9.

75. Gannon CJ, Izzo F, Aloia TA, Pignata S, Nasti G, et al. Can hepatocellular cancer screening increase the proportion of long-term survivors? Hepatogastroenterology 2009;56:1152-6.

76. McMahon BJ, Bulkow L, Harpster A, Snowball M, Lanier A, et al. Screening for hepatocellular carcinoma in Alaska natives infected with chronic hepatitis B: a 16-year population-based study. Hepatology 2000;32:842-6.

77. Bolondi L, Sofia S, Siringo S, Gaiani S, Casali A, et al. Screening programme of cirrhotic patients for early diagnosis and treatment of hepatocellular carcinoma: a cost-effectiveness analysis. Gut 2001;48:251-9.

78. Toyoda H, Kumada T, Kiriyama S, Sone Y, Tanikawa M, et al. Impact of surveillance on survival of patients with initial hepatocellular carcinoma: a study from Japan. Clin Gastroenterol Hepatol 2006;4:1170-6.

79. Zhang B, Yang B. Combined alpha fetoprotein testing and ultrasonography as a surveillance test for primary liver cancer. J Med Screen 1999;6:108-10.

80. Marrero JA, Feng Z, Wang Y, Nguyen MH, Befeler AS, et al. Alpha-fetoprotein, des-gamma carboxyprothrombin, and lectin-bound alpha-fetoprotein in early hepatocellular carcinoma. Gastroenterology 2009;137:110-8.

81. Chang CC, Chen HH, Chang YC, Yang MY, Lo CM, et al. Computer-aided diagnosis of liver tumors on computed tomography images. Comput Methods Programs Biomed 2017;145:45-51.

82. Sastre J, Díaz-Beveridge R, García-Foncillas J, Guardeño R, López C, et al. Clinical guideline SEOM: hepatocellular carcinoma. Clin Transl Oncol 2015;17:988-95.

83. Pocha C, Dieperink E, McMaken KA, Knott A, Thuras P, et al. Surveillance for hepatocellular cancer with ultrasonography vs. computed tomography-a randomised study. Aliment Pharmacol Ther 2013;38:303-12.

84. Fukugawa Y, Namimoto T, Toya R, Saito T, Yuki H, et al. Radiation-induced liver injury after 3D-conformal radiotherapy for hepatocellular carcinoma: quantitative assessment using Gd-EOB-DTPA-enhanced MRI. Acta Med Okayama 2017;71:25-9.

85. Braillon A. Hepatocellular Carcinoma Screening: Seeking Robust Evidence. Gastroenterology 2019;156:288-9.

86. Gounder PP, Bulkow LR, Meltzer MI, Bruce MG, Hennessy TW, et al. Cost-effectiveness analysis of hepatocellular carcinoma screening by combinations of ultrasound and alpha-fetoprotein among Alaska native people, 1983-2012. Int J Circumpolar Health 2016;75:31115.

87. Sarkar M, Stewart S, Yu A, Chen MS, Nguyen TT, et al. Hepatocellular carcinoma screening practices and impact on survival among hepatitis B-infected Asian Americans. J Viral Hepat 2012;19:594-600.

88. Tong MJ, Sun HE, Hsien C, Lu DS. Surveillance for hepatocellular carcinoma improves survival in Asian-American patients with hepatitis B: results from a community-based clinic. Dig Dis Sci 2010;55:826-35.

89. Hong TP, Gow PJ, Fink M, Dev A, Roberts SK, et al. Surveillance improves survival of patients with hepatocellular carcinoma: a prospective population-based study. Med J Aust 2018;209:348-54.

90. Chen JG, Zhang BC, Lu JH, Chen QG, Yun ZX, et al. Review in progress of liver cancer screening in Qidong. China Cancer 1996;5:11-3. (in Chinese)

91. Chen JG. Survival analysis of 5380 registered patients with liver cancer. Chin J Cancer 1984;3:254-7. (in Chinese)

92. Yang BH, Liu KD, Tang ZY. Prelimary analysis of liver cancer screening in high risk population. Tumor 1987;7:82-3. (in Chinese)

93. Chen JG, Zhang BC, Jiang YH, Wang MR, Lu JH, et al. Studdy on screening for PLC in high risk population of an endemic area. Chin J Prev Med 1991;25:325-8. (in Chinese)

94. Zhou XP, Chen QG, Yun ZX, Shen QJ, Zhang H, et al. Determination of screening interval for liver cancer: a nested case-control study. J Nanjing Railw Med College 1996;15:226-8. (in Chinese)

95. Dong ZW, Qiao YL. The practice and discussion of population-based cancer screening program in China. China Cancer 2009;19:6869. (in Chinese)

96. Dong ZW. Chinese technical protocols for early diagnosis and treatment of cancer. 1st ed. Beijing: People's Medical Publishing House. 2009; pp. 154-84. (in Chinese)

97. Chen JG, Zhang YH, Zhu J, Lu JH, Wang JB, et al. Early diagnosis and early treatment of liver cancer in Qidong: survival of patients 
and effectiveness. Chin J Oncol 2017;39:946-51. (in Chinese)

98. Bureau of Disease Control of National Health Commission of PR China, China Cancer Foundation, Expert Committee on Rural Cancer Project on Early Detection and Early Treatment. Project report on cancer early detection and early treatment (rural area): $2017-$ 2018. Beijing: People's Medical House Press; 2018. pp. 26-30. (in Chinese)

99. Breau of Disease Control of National Health Commission of PR China. Technical Protocols for Early Diagnosis and Treatment of Cancer in Huaihe River Basin. Available from: http://www.doc88.com/p-4334139219880.html. [Last accessed on 6 Jan 2019].

100. Dai M, Shi JF, Li N. Design and prospective target of the cancer screening program in Urban China. Chin J Prev Med 2013;47:179-82. (in Chinese)

101. Qiu WQ, Shi JF, Guo LW, Mao AY, Huang HY, et al. Medical expenditure for liver cancer in urban China: a 10-year multicenter retrospective survey (2002-2011). J Can Res Ther 2018;14:163-70.

102. Ji M, Liu Z, Chang ET, Yu X, Wu B, et al. Mass screening for liver cancer: results from a demonstration screening project in Zhongshan City, China. Sci Rep 2018;8:12787.

103. Sherman M, Bruix J. Screening for liver cancer: the rush to judgment. Ann Intern Med 2012;157:300-1; author reply 301-2.

104. Kansagara D, Papak J, Pasha AS, O’Neil M, Freeman M, et al. Screening for hepatocellular carcinoma in chronic liver disease: a systematic review. Ann Intern Med 2014;161:261-9.

105. Bruix J, Sherman M, American Association for the Study of Liver Diseases. Management of hepatocellular carcinoma: an update. Hepatology 2011;53:1020-2.

106. Poon D, Anderson BO, Chen LT, Tanaka K, Lau WY, et al. Management of hepatocellular carcinoma in Asia: consensus statement from the Asian Oncology Summit 2009. Lancet Oncol 2009;10:1111-8.

107. Ferenci P, Fried M, Labrecque D, Bruix J, Sherman M, et al. Hepatocellular carcinoma (HCC): a global perspective. J Clin Gastroenterol 2010;44:239-45.

108. European Association for the Study of the Liver, European Organisation For Research And Treatment Of Cancer. EASL-EORTC clinical practice guidelines: management of hepatocellular carcinoma. J Hepatol 2012;56:908-43.

109. Kudo M, Izumi N, Kokudo N, Matsui O, Sakamoto M, et al. Management of hepatocellular carcinoma in Japan: consensus-based clinical practice guidelines proposed by the Japan Society of Hepatology (JSH) 2010 updated version. Dig Dis 2011;29:339-64.

110. Zhou J, Sun HC, Wang Z, Cong WM, Wang JH, et al. Guidelines for diagnosis and treatment of primary liver cancer in China (2017 edition). Liver Cancer 2018;7:235-60.

111. Sharma P, Saini SD, Kuhn LB, Rubenstein JH, Pardi DS, et al. Knowledge of hepatocellular carcinoma screening guidelines and clinical practices among gastroenterologists. Dig Dis Sci 2011;56:569-77.

112. Lederle FA, Pocha C. Screening for liver cancer: the rush to judgment. Ann Intern Med 2012;156:387-9.

113. Kerry SM, Bland JM. Analysis of a trial randomised in clusters. BMJ 1998;316:54.

114. Petruzziello A. Epidemiology of Hepatitis B Virus (HBV) and Hepatitis C Virus (HCV) Related Hepatocellular Carcinoma. Open Virol J 2018;12:26-32.

115. Law M. Screening without evidence of efficacy. BMJ 2004;328:301-2.

116. Moon AM, Weiss NS, Beste LA, Su F, Ho SB, et al. No association between screening for hepatocellular carcinoma and reduced cancer-related mortality in patients with cirrhosis. Gastroenterology 2018;155:1128-39.e6.

117. Lersritwimanmaen P, Nimanong S. Hepatocellular carcinoma surveillance: benefit of serum alfa-fetoprotein in real-world practice. Euroasian J Hepatogastroenterol 2018;8:83-7.

118. Poustchi H, Farrell GC, Strasser SI, Lee AU, McCaughan GW, et al. Feasibility of conducting a randomized control trial for liver cancer screening: is a randomized controlled trial for liver cancer screening feasible or still needed ? Hepatology 2011;54:1998-2004

119. Trevisani F1, D’Intino PE, Morselli-Labate AM, Mazzella G, Accogli E, et al. Serum alpha-fetoprotein for diagnosis of hepatocellular carcinoma in patients with chronic liver disease: influence of HBsAg and anti-HCV status. J Hepatol 2001;34:570-5.

120. Aghoram R, Cai P, Dickinson JA. Alpha-foetoprotein and/or liver ultrasonography for screening of hepatocellular carcinoma in patients with chronic hepatitis B. Cochrane Database Syst Rev 2012;CD002799.

121. Sherman M. Alphafetoprotein: an obituary. J Hepatol 2001;34:603-5.

122. Sherman M. Serological surveillance for hepatocellular carcinoma: time to quit. J Hepatol 2010;52:614-5.

123. Forner A, Reig M, Bruix J. Alpha-fetoprotein for hepatocellular carcinoma diagnosis: the demise of a brilliant star. Gastroenterology 2009; 137:26-9.

124. Cole P, Morrison AS. Basic issues in population screening for cancer. J Natl Cancer Inst 1980;64:1263-72.

125. Prorok PC. Epidemiologic approach for cancer screening. Problems in design and analysis of trials. Am J Pediatr Hematol Oncol $1992 ; 14: 117-28$

126. Fong ZV, Tanabe KK. The clinical management of hepatocellular carcinoma in the United States, Europe, and Asia: a comprehensive and evidence-based comparison and review. Cancer 2014;120:2824-38.

127. Cancer Research UK. Liver cancer. 2016. Available from: http://www.cancerresearchuk.org/about-cancer/liver-cancer/gettingdiagnosed/screening. [Last accessed on 20 Dec 2018]

128. Simonetti J, Bulkow L, McMahon BJ, Homan C, Snowball M, et al. Clearance of hepatitis B surface antigen and risk of hepatocellular carcinoma in a cohort chronically infected with hepatitis B virus. Hepatology 2010;51:1531-7.

129. Kumar A. Current practices in management of hepatocellular carcinoma in India: results of an online survey. J Clin Exp Hepatol 2014;4:S140-6.

130. Eltabbakh M, Zaghla H, Abdel-Razek W, Elshinnawy H, Ezzat S, et al. Utility and cost-effectiveness of screening for hepatocellular carcinoma in a resource-limited setting. Med Oncol 2015;32:432.

131. Ayuso C, Rimola J, Vilana R, Burrel M, Darnell A, et al. Diagnosis and staging of hepatocellular carcinoma (HCC): current guidelines. Eur J Radiol 2018;101:72-81. 
132. Shih ST, Crowley S, Sheu JC. Cost-effectiveness analysis of a two-stage screening intervention for hepatocellular carcinoma in Taiwan. J Formos Med Assoc 2010;109:39-55.

133. Lee YJ, Lee JM, Lee JS, Lee HY, Park BH, et al. Hepatocellular carcinoma: diagnostic performance of multidetector CT and MR imaging-a systematic review and meta-analysis. Radiology 2015;275:97-109.

134. Li Q, Liu F, Wei YG, Li B. Quality assessment of Chinese clinical practice guidelines of primary hepatic carcinoma from 2016 to 2017. Chin J Evidence-Based Med 2018;18:1109-13. (in Chinese)

135. Peterson MS, Baron RL, Marsh JW Jr, Oliver JH 3rd, Confer SR, et al. Pretransplantation surveillance for possible hepatocellular carcinoma in patients with cirrhosis: epidemiology and CT-based tumor detection rate in 430 cases with surgical pathologic correlation. Radiology 2000;217:743-9.

136. Lv GS, ChenL, Wang HY. Research progress and prospect of liver cancer in China. Chin Bull Life Sci 2015;7:237-48. (in Chinese)

137. Waidely E1, Al-Yuobi AR, Bashammakh AS, El-Shahawi MS, Leblanc RM. Serum protein biomarkers relevant to hepatocellular carcinoma and their detection. Analyst 2016;141:36-44.

138. Anwar SL, Lehmann U. MicroRNAs: emerging novel clinical biomarkers for Hepatocellular Carcinomas. J Clin Med 2015;4:1631-50.

139. Lou J, Zhang L, Lv S, Zhang C, Jiang S. Biomarkers for Hepatocellular Carcinoma. Biomark Cancer 2017;9:1-9.

140. Lok AS, Sterling RK, Everhart JE, Wright EC, Hoefs JC, et al. Des-gamma-carboxy prothrombin and alpha-fetoprotein as biomarkers for the early detection of hepatocellular carcinoma. Gastroenterology 2010;138:493-502.

141. Yang JD, Patel T. Early detection of hepatocellular carcinoma-expanding the utility of circulating tumor Markers. Hepatology 2019;69:1855-7.

142. Duarte-Salles T, Misra S, Stepien M, Plymoth A, Muller D, et al. Circulating osteopontin and prediction of hepatocellular carcinoma development in a large European population. Cancer Prev Res (Phila) 2016;9:758-65.

143. Rabeneck L, Lansdorp-Vogelaar I. Assessment of a cancer screening program. Best Pract Res Clin Gastroenterol 2015;29:979-85.

144. Jung M. National cancer screening programs and evidence-based healthcare policy in South Korea. Health Policy 2015;119:26-32.

145. Beste LA, Ioannou GN, Yang Y, Chang MF, Ross D, et al. Improved surveillance for hepatocellular carcinoma with a primary careoriented clinical reminder. Clin Gastroenterol Hepatol 2015;13:172-9.

146. Roskilly A, Rowe IA. Surveillance for hepatocellular cancer. Clin Med (Lond) 2018;18:s66-9.

147. WHO. Screening for various cancers. Available from: https://www.who.int/cancer/detection/variouscancer/en/. [Last accessed on 6 Jan 2019] 